\title{
Redefining the theory of Engineering for Relevance in the 21st Centuryin Africa
}

\author{
Kehdinga George Fomunyam
}

\begin{abstract}
Academia and professionals' attention has been drawn towards redefining theory of engineering for relevance in the 21st century. This has become an imperative as it has brought changes in engineering courses, and yet engineering curriculum have not been modified to accommodate these changes. With increased intellectual demand for ground-breaking engineering performance in Africa, African engineering institutions are still lagging behind as they are yet to meet up with the 21st century needs; hence the crux of this paper. This paper was guided by Jean Piaget's constructivism learning theory, focusing on individual's understanding and knowledge, rooted on one's experience erstwhile to learning setting. This paper takes a broad look at the overall investigation of redefining the theory of engineering for relevance in 21st century in Africa. The specific objectives explore the principles of theory of engineering as well as its applicability and to examine how theory of engineering can be improved for contextual relevance, as well as its implications for 21st centuryengineering curriculum. Thus, to address this gaps, recommendations on redefinition and relevance of theory of engineering pertaining to curriculum revision and providing adequate staff development for engineering educators with intellectual capacityand skill improvement were recommended.

Keywords: Africa, Engineering education, curriculum, redefining, theory of engineering
\end{abstract}

\section{INTRODUCTION}

Theory of Engineering in the 21st century remain central in promoting engineering practices, which stimulate nation's economic growth and development globally. However, several inquiries and concerns on theory of engineering in engineering education (EE) in the twenty-first century, are quite different from those in 20th century (OECD, 2016). The "who, what, where and how" of redefining theory of engineering in EE have led to significant changes over past decades. EE as well as the principles of theory of engineering has been basically transformed by disintegration and combined, or interchanged easily by invention, development of information and communications technology (ICT)-permitted service that are embedded in engineering theory and practices (Garg et al., 2015). The origin of theory of engineering in EE has been documented to illustrate and reflects main characteristics of modifications, that highlights the importance of redefining the relevance of theory of engineering in EE in the 21st century(Mejia et al., 2017; 2018). Engineering transformation has led to valuable investments in EE that has made productive assets through remarkable improvement in theoretical and conceptual knowledge and skills (Bhattacharya et al., 2015; 2018).

* Correspondence Author

Dr. Kehdinga George Fomunyam*, Institute for Systems Science Durban University of Technology.E-mail. georgek@dut.ac.za

(C) The Authors. Published by Blue Eyes Intelligence Engineering and Sciences Publication (BEIESP). This is an open access article under the CC BY-NC-ND license (http://creativecommons.org/licenses/by-nc-nd/4.0/)
Revised Manuscript Received on October 25, 2020.

Thus, engineers create, innovate and develop as well as conduct rigorous research to develop methods and tools that enable practicing engineers to solve complex and social issues more effectively, systematically and efficiently. EE focus more on imparting knowledge and skills required in practicing engineering, by ensuring theory development of new engineering methods and tools (Sachs et al., 2017; Okay-Somerville and Scholarios, 2017).Also, increased impact on important social predispositions have grave impacts on EE involving building knowledge-driven engineering courses, which assist in redefining theory of engineering. Notably, paroxysm of new knowledge, dwelling on tenets of globalization and demographic change has fuel academia and professionals to invest in research in promoting engineering discipline(Lloyd et al., 2015).

Thus, redefining theory of engineering has remained competitive in EE, as its focus is not only directed towards improved productivity, but also in innovation and modernization of outstanding research for the next generation of technologies (Jackson and Wilton, 2016; Kaider et al., 2017). In this 21st century with high-tech society, becomes imperative to educate and equip engineering students to have a strong foundation in theory of engineering and its principles. Several studies have documented that theory of engineering and its relevance should be included in engineering modules and curriculum(Jackson and Wilton, 2016; Sachs et al., 2017; Okay-Somerville and Scholarios, 2017). On the other hand, it is utmost true that in Africa in the 21st century, engineering curriculum has not go through any key changes since the introduction of engineering science in the 1960's (Mejia et al., 2017; 2018). It is important for engineering educators and professionals as well as stakeholders take cognizance of the major changes in engineering fields, as this will help in reshaping engineering curriculum.

This paper presents a systematic review methodology by exploring redefining the theory of Engineering for relevance in the 21st century in Africa. This systematic review method identifies and appraise published articles from year 2015 to 2020in the fields of Engineering, Education and Philosophy systematically. The methodology aim is to evaluate published reviews in redefining theory of engineering for relevance in 21st century,and to explore and discuss its implications in order to provide the best recommendations to engineering academia and professionals as well as germane stakeholders. The main objective of this paper is to fill the research gap by contributing to the overall understanding of redefining theory of engineering for its 21st century relevance in Africa.

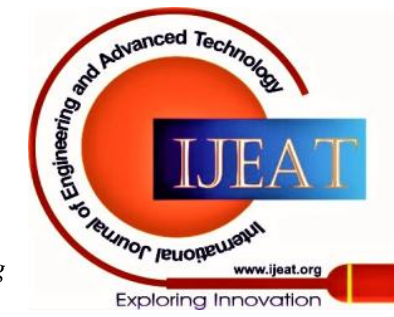


Specifically, we explore the principles of the theory of engineering and its applicability to 21st century; and seeking to improve on the theory of engineering for contextual relevance; as well as its implications for EE in the 21st century in Africa, hence, recommendations were advocated.

\section{METHODOLOGICAL APPROACH}

A systematic literature review was conducted as recommended by Mallett et al. (2012) and Ouhbi et al. (2015)where the authors derived formulated review questions, identified relevant studies, selected studies that fit the inclusion criteria, and evaluated the quality of the research studies, as well as summarized the evidence by use of an unambiguous methodology. Based on the research questions of this study, relevant studies were identified through the reviewed articles database. The descriptors "theory of engineering", "relevance of theory of engineering", "redefinition of engineering theory", and theory of engineering in EE" were used to locate primary sources. These descriptors were also used in combination with other descriptors such as "in Africa", "across the globe", "in the 21 st century", "America", Asian", and "Africa demographics" as these are all underrepresented variables in EE as well as in engineering profession (Leandro Cruz et al., 2019). Several articles (Ouhbi et al. 2015; Trevelyan, 2019) were identified as potential sources of information, but to assess their quality, only articles that met the following inclusion criteria were reviewed: (1) Published between 2015 and 2020; (2) enumerated redefinition of theory of engineering as one of the lenses for analysis; and (3) examined relevance of theory of engineering in Africa in the 21st century in EE. The papers were divided into sub-sections relating to the study objectives as well as the types of analytical themes itemized in the diverse manuscripts identified. In total, there were 33 articles reviewed representing a wide variety of analytical research papers. Of those 33 articles, only 28 clearly identified the redefining of theory of engineering for relevance in Africa in 21st century in engineering education were used. The other five articles simply indicated that the themes used or developed were more of "critical theoretical papers". To summarize the substantiation found in these identified articles, a coding sheet was developed based on the features significant to each study appraised. These classifications on the coding sheet included identifying the study's objectives, the research questions, the methods, the type of data collected, the population involved in the study, and relevant findings. Additionally, the methods used to identify, evaluate and review the published articles systematically, are drawn from existing studies (Leandro Cruz et al., 2019;Trevelyan, 2019), following scientific research practices in the conduct and reporting of systematic reviews are explicitly explained. After reviewing the articles, the principal investigator synthesized the preliminary findings and patterns recorded in notes. The author reviewed the notes and preliminary findings to guide the final review. After the articles were analyzed, the principal investigator developed a representative sampling frame in which the articles were used to outlined the research questions. These representative examples were not taken verbatim, but rather synthesized to illustrate how analytical research in EE can reframe to redefine major themes in theory of engineering research questions, as indicated by Bornasalet al. (2018) and Wilson-Lopez et al.(2020), when guided by analytical theories of engineering. In addition, the process of identifying and appraising all published reviews allows researchers to describe the quality of the compiled existing studies, summarize and compare the conclusions of the reviews as well as discussing the implications and recommendations of the conclusions of the reviews (Bornasalet al., 2018; Wilson-Lopez et al., 2020). The principles of systematic review methodology were emphasized in the studies to describe how theory of engineering are redefined for relevance in EE are primarily enacted (Bornasalet al., 2018; Trevelyan, 2019; Wilson-Lopez et al., 2020). In the discussion section, we illustrated how we outlined representative research questions presented in the reviews highlighted by the studies analyzed.

\section{LIMITATIONS}

While this study focused on published articles related to redefining of theory of engineering for 21st century relevance, it is possible that the authors may have omitted studies on "STEM" that may have included theory of engineering in social engineering and demographic areas of research. Furthermore, it is documented that by selecting publications from 2015 to 2020, the principal investigator may have omitted earlier studies that discuss redefinition and relevance of theory of engineering in the 21st century. However, the focus of this work was to explore the state-ofthe-art of these types of studies on theory of engineering in EE. Finally, we want to acknowledge that some of the studies reviewed used more than one analytical theoretical framework. However, within our inclusion criteria, we focused on studies that used at least one analytical context and did not analyze the impact of those that may have used a combination of these outlines.

\section{OVERALL LITERATURE REVIEW}

In 21st century, critical theoretical frameworks are used to challenge social practices and belief systems in engineering, yet it requires educators and professionals to dig deeper into the consequences of demanding research whose foci and approach situate underrepresented engineering graduates as deficient in skills development (Holmes, 2017; Hall et al., 2017). Deficit perspectives prevent many underrepresented students and educators from participating in important learning and teaching activities, which further act as a disadvantage to students (Chillas et al., 2015). Critical reflection, in particular, is central as it uncovers power dynamics that exist in EE, challenging hegemonic assumptions on theory of engineering (Holmes, 2017).

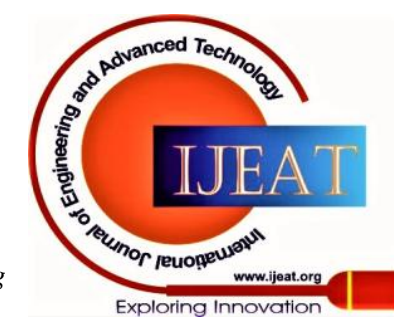


One key driving force for theory of engineering in EE is the shifting focus towards developing students' 21 st century skills, which are redefined as the skills and abilities required for success in societies or workplaces in response to societal, economic, technological and globalization changes (OECD/ACET, 2020). There are also identified missing gaps in redefining theory of engineering in Africa, as dearth of collaboration between engineering educators, and professionals has generated a weak policy framework, that are not in favor of students, and not aligned with rapidand flexible changing industrial partnership for 21st century skills (Kodongo and Ojah, 2016). In addition, 21st century skills require a need for building engineering students with life skills as they are typically defined around theory of engineering pertaining to social matters and development. Redefining the theory of engineering for relevance in EE in the 21st century in Africa advocates for strong EE workforce, that will strengthen and complements structural design of engineering as a field. If it is embraced in EE, a continuous cycle of improvement in redefining theory of engineering for relevance will better meet students' learning needs and reduce inequalities in classwork participation and attainment (Mein et al., 2018). Hence, strengthening EE is critical in reducing learning gap in the 21st century engineering curriculum and courses. The goal is to ensure that EE students are guaranteed access to participate in high quality realistic productive learning, that will develop them with appropriate 21st century skills (Pawley et al., 2018).

However, a likely response to a growing focus on various 21st century skills, have been made to identified major content-related changes to engineering curriculum in past two decades. These changes include some notable omissions of the 21st century skills that are central to the curriculum that can improve the knowledge content of engineering curriculum(Morell, 2016). This, however, will require remarkable changes in structural assessments via leaning modules and new methodologies. These trends in curriculum assessment requires profound changes,significantly aligned with redefining theory of engineering and its relevance, with new knowledge content and teaching practices required to improveEE curriculum (Morell, 2016; Pawley et al., 2018). Thus, the combination challenges in improving educational outcomes may prompt reimagining of EE and its prospects. The aim is to enable engineering educators to devote more time in developing themselves in teaching and learning 21st century skills that will be beneficial to students from the professional level including specialists (Viegas et al., 2016).

Significantly, EE staff should act as front line professionals,in collaborating and working with students in bringing out clearly defined roles that are matched with engineering standards that will enhanced redefining theory of engineering(Viegas et al., 2017; Mejia et al., 2018). Equally and importantly, faculty members need adequate working conditions and institutional support including regular funding, to enable them to carry out their roles effectively(Viegas et al., 2016; 2017).Besides, educational stakeholders have a key role to play in organizing suitable development opportunities and resources to meet the basic needs and facilitate collaboration between public-private partnership and higher learning institutions.
Collaborative practices should be ensured between engineering educators and professional networks, as it will support and develop appropriate contextual pedagogic approaches, that will provide important mechanism for engineering educators to be accountable to students(Kodongo and Ojah, 2016). Learning to collaborate and work effectively within teams will need to be central to professional learning as redefining theory of engineering for its relevance will reinforce a variety of collective culture within educational systems(Garg et al., 2015). Therefore, the increasingly availability to circumscribe to 21st century demands enhanced capabilities from faculty members in engineering institutions to explore, find, discuss, select, create and share ideas and experiences in obliging its significance in theory of engineering redefinition in Africa.

Exploring the Principles and Applicability of Theory of Engineering in 21st Century

The Millennium Development Goals (MDGs) have been substituted by Sustainable Development Goals (SDGs), and this set of goals is broader than MDGs, covering a lot of issues. Thus, education target is focused on access to education and learning quality as well as lifelong learning schemes (Kaider et al., 2017). Hence, SDG targets explicitly stated learning, proficiency, and a variety of other skills and competencies, are mainly connected to education and technological impact for sustainable economic growth and development (Oliver, 2015). The SDGs presented a significant constitutional prospect to make enormous change within the present universal context, by improving the relevance of educational systems across extensiveness of skills development. An in-depth evaluation of various life skills educational programmes as outlined by UNICEF (2012) and Sustainable Development Goal (SDG) 4 (OECD, 2016)focused on literacy and skill development allied with global technological improvements with respect to cultural diversity for sustainable development, especially in Africa.

Engineering graduates who opt for engineering career path are being obliged to comply with the demanding challenges of 21st century. Their expertise is not only focus on scientific and technological aspects, but also on skills and social characteristics such as teamwork, creativity or leadership (Hall et al., 2017). Redefining theory of engineering for relevance are tailored towards building engineering programmes and curriculum around traits required in fourth industrial revolution (4IR) era with hightech impact. Also, engineering education must stress the importance competences through teaching and learning and therefore, academic and professionals need to align in these new guidelines (Kaider et al., 2017). This will further enable students to realize the importance of learning that involves technological impact on nation's economic growth. This will foster a very demanding skill development, especially because it involves better opportunities to develop scientific and social competences, via working on course contents collaboratively and cooperatively with their counterparts(Garg et al., 2015).

Published By:

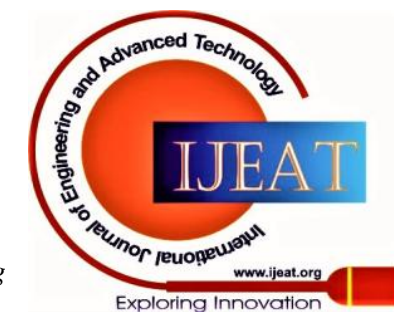


Engineering educators and professional must come together to work on research projects that will be a great advantage to students, to enable them to develop personal and effective skills in order to embrace the 21st century challenges (Bhattacharya et al., 2018). On the other hand, 21st century students must be mastery of ICT tools and skills, to enable them to compete within or outside learning environment. It becomes very important as engineering educators must see it as their duty to facilitate and provide learning opportunities in improving engineering graduates with their expertise in several engineering-based applications (Mejia et al., 2018). Engineering educators must be competent to develop themselves and be allied with upgraded curriculum to produce best graduate students.

Regular engineering symposium and curriculum stakeholders' meetings should be held to address topics that are up-to-date with the 21st century requirements (Lloyd et al., 2015). Providing these forums where considerations such as curriculum upgrade and students' skills development can be presented and discussed between academics, students and professional engineers. This will foster new insights and perspectives that will aid educators to reflect on their professional development.

Notably, engineering students are less motivated, as they realize the gap between what they are learning and the technology they use. Also, the 21st century employers are getting frustrated as a result of fresh graduates from the university have poor mastery of the latest programming language or design methodology (Viegas et al., 2016; 2017). And yet, engineering curriculum have changed little over the last decades. Curriculum should be upgraded to the 21st century requirements,enabling engineering educators to equip fresh graduates with basic and market requirements with skills required for 4IR. Engineering students should be equipped with knowledge and skills, that will make them to become a life-long learner, which is the only way to survive in a technological and engineering profession (Lloyd et al., 2015). To achieve and balance these conflicts, engineering educators need to change how students learn by fostering inclusion of students in research and mentoring towards continuing EE.

\section{Ways Forward to Improve on the Theory of Engineering for Contextual Relevance}

Modernization are playing out new demographic dynamics, including different patterns of changing social characteristics, and rapid transformation as well as globalization in Africa. The United Nations (UN) estimated the continent's population to be nearly double from 1.3 billion in 2019 to 2.4 billion in 2050 during standard population projection. The population growth in subSaharan African countries were projected to account for more than half of the world's population growth (OPHDI, 2015; OECD, 2016). Besides, Africa has the highest labor force growth rate in the world, yet millions of young people are still looking for jobs and educational opportunities. To develop infrastructure in Africa, one of the key strategies is to create new economic settings that are highly value-added through which demographic dividends can be harnessed for public and private entrepreneurship and potentials (OECD, 2016).
However, jointly with immense opportunities of scientific and technological transformation, has brought new remarkable and difficult emerging ethical enquiries (Oliver, 2015). In redefining theory of engineering for relevance, engineering educators and students are expected to embrace 21st century approach in teaching and learning as this is critical to this present day learning environment (Bridgstock, 2017). Besides, getting engineering educators to use recent technology and different approach in teaching,learning and handling high-tech educational facilities is critical in building theory of engineering (Sachs et al., 2017). The key theme in redefining theory of engineering is to make sure engineering educators are possessed with hard and soft skills such as engaging in multitasking and accessing information using modernized technology for problem-solving problems in social learning environment with unrestricted freedom of using technology for learning in 21st century in Africa (Reddan, 2017).

Thus, an effective workforce is critical to EE programmes and engineering educators are central to educational workforce, as talented educators are essential to improve students' learning outcomes (Sachs et al., 2017). But multiple challenges still prevail in EE in Africa, as teaching is neither attractive nor publically valued as career choice and gender imbalances are found across teaching workforce. Other factors standing as barriers include rising demands for education requires teachers with subject knowledge, and outdated curriculum prospectus as well as limited support from professional bodies. Hence, providing universal access to quality education demands addressing these challenges with new complete clarifications in theory of engineering in EE (Hall et al., 2017; Holmes, 2017). As profound changes and new thinking are needed in guaranteeing engineering students to adequately prepare for their future career in an increasingly unreliable, unequal and unstable working environment. Various theoretical tools in theory of engineering are employed to aid engineering professionals and studentsto offer themselves better analytically and rigorous support in making engineering relevance (Bilgin et al., 2017). EE has been changing with time and the desire to achieve these best practices requires a clear theoretical and conceptual framework. Redefining theory of engineering for relevance in EE requires rigorous research activities, involving modernized methodology in combining theory and practice in engineering learning environment. This typical choice between application-based or theory-based techniques has become an imperative in engineering research institutes(Burke et al., 2016; Bridgstock, 2017). Importantly, it has been advocated for a change in EE research to be more laborious in using methods and philosophies drawn from other disciplines. Professionally, teaching the right modules aligned with 21st century curriculum is essentialin today contemporary era, as initiatives in building engineering students with the right skills for career development becomes necessary.

Published By:
Blue Eyes Intelligence Engineering and Sciences Publication (C) Copyright: All rights reserved.

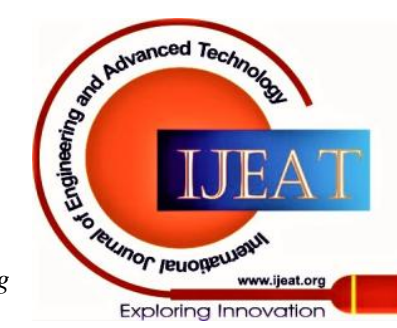


Due to these developments, standards of learning and teaching should be higher in the 21st century than previous century (Jackson and Wilton, 2016). Engineering fields have been made to acquire additional knowledge and intellectual content as well as skills development, both in general and specific to be able to survive and be successful in the 21st century. Growing evidence has demonstrated that faculty members equipped with educational resources, must developed their intellectual abilities, that are especially critical in contributing to students' learning and consequently, tending towards advancing the success of a nation via economic, social and political spheres (Hall et al., 2017; Sachs et al., 2017).

\section{THEORETICAL FRAMEWORK}

This paper was guided by Constructivism learning theory, which can be traced back to educational psychology in the work of Jean Piaget (1896-1980) identified with Piaget's theory of cognitive development (Piaget, 1971; Nola and Irzik, 2006). This theory was used to explain the underlying factors in redefining theory of engineering for relevance in the $21 \mathrm{st}$ century. The theory implied that learner's understanding and knowledge are based on their own experiences prior to entering learning environment. This is majorly concerned with rational classifications of knowledge and justificational basis (Matthews, 1998; Anderson et al., 1998). Hence, constructivism theory acknowledged that learner has prior knowledge and experiences, often determined by social and cultural environment. Thus, learning is done by students' creating knowledge out of their experiences, while educators need to know what students are thinking, and how to improve students' logical reasoning (Seifert and Sutton, 2009; Nowak et al., 2018).

However, the challenges for EE policy making are so numerous, ranging from how to reduce dependence on resource-driven progression patterns, handling effects of the previous ingenuousness of thrifts, encouraging sectoral modification through learning and amassing competences, nurturing broad improvement and insufficiency cutback of resources (Bilgin et al., 2017). Furthermore, focusing a great attention concerns pertaining to recruitment, selection, preparation and deployment of engineering educators, will go a long way in producing outstanding engineering graduates in Africa in 21st century (Garg et al., 2015; Viegas et al., 2017). Therefore, in redefining theory of engineering for relevance in African universities in the 21st century, requires EE to break from its outdated educational practices and work towards meeting the demands of delivering high-quality teaching to engineering students involving theory and practical courses (Trede and McEwen, 2016). In addition, Piaget focused on how humans make meaning in relation to interaction between experiences and ideas. His views focused on human development in relation to what is occurring with an individual as distinct from development influenced by other persons (Piaget, 1971; Anderson et al., 1998; Sarkar, 2016). The validation of constructivism from within-the-human evaluation is ascribed to enunciated means by which information from environment and ideas from individual interact, resulting in an internalized structures developed by learners. Consequently, assimilation and accommodation can be classified as key activities in interaction strategies as individuals construct new knowledge from their experiences (Atkinson et al., 2000; Garg et al., 2015). When individuals assimilate new knowledge, they integrate it into an already preponderant context without changing the previous one. While accommodation is the process of reframing one's mental exemplification of the external domain to fit firsthand proficiencies (Atkinson et al., 2000; Garg et al., 2015) Similarly, EE involves learning that occurs within and outside the institutions, encompassing better opportunities in learning relevant experiences from professionals. Across the globe, a lot of efforts have been made in improving EE towards redefining theory of engineering, yet poor quality in $\mathrm{EE}$ has become a great challenge for uncertain future for engineering graduates in Africa (Bhattacharya and Jeorg, 2018; Mejia et al., 2018). Therefore, engineering graduates are required to gain access to high-quality educational system, with relevant 21st century skills to build and redefine engineering programmes that encompasses redefining theory of engineering for its relevance in Africa. This becomes an imperative top policy issue in African education in addressing social and economic realities involving engineering impacts.

\section{Discussion}

The 21st century has emerged as the beginning of the Digital Age at a time of unprecedented growth intechnology with higher knowledge information. Significantly, connecting the knowledge content to real-world application and social issues situations has enabled educational stakeholder to build different learning environments to aid students to see how and what they are learning connects with their lives and the world around them (Viegas et al. 2016; 2017). A lot of emphasis has been made to reveal the importance of building the learning facilities on projectsbased, requires students to use content knowledge in new ways and to extend their understanding through collaboration with their counterparts (Kodongo and Ojah, 2016). This will aid students to understand and overseer their thinking processes they are using by including metacognitive behaviours that will aid effective rational thinking. EE have made use of educational technology to aid engineering students in accessing, analysing, organizing and sharing what they are learning and by allow students to independently locate appropriate methodological tools for engineering tasks in the future (Bates and Hayes, 2017; Pawley et al., 2018). Redefining the theory of engineering for its relevance in EE may provide opportunities for engineering students to become originators as well as users of available knowledge by providing prospects for creating and verifying their own entries in collaborative locations and assessing roles of others (Pawley et al., 2018). Thus, engaging students in solving complex problems that require higher order thinking and application of knowledge content, has resulted into new perspectives and provide solutions to social and engineering problems.

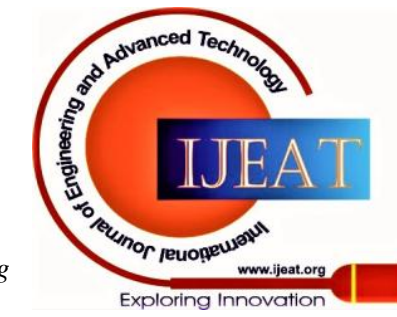

C Copyright: All rights reserved. 
This has supported the idea of postulating opportunities for engineering students to work collaboratively as they gather information, solve problems, share ideas, and spawn new ideas that will imbibe redefining theory of engineering for relevance in EE in the 21st century (Blackmore et al., 2016; Mein et al., 2018). Also, developing life and career skills among engineering students has created opportunities to make them self-directed beginners taking responsibility for their own learning and who learn how to work effectively with others. Engineering educators must take it upon themselves to help students to make connections between subjects, concepts and ideas and with others, including those outside the learning environment. Remarkably, the main keys to integrating redefining theory of engineering for relevance for 21st century skills and curriculum modules include engineering application, connections and participation (Kaider et al., 2017).

Importantly, the role of engineering educators in the 21st century is key and as they shift from that of the expertise to that of being facilitator of knowledge, as the focus for instruction shifts from knowing to being able to use and apply information in relevant ways. Engineering students should be prepared for the 21st century involving continuous cycles of learning that tends to lead to deeper understanding of subject area content and developing critical skills for meeting future challenges (OPHDI, 2015; Holmes, 2017). However, the basic tenets of STEM have recorded success in the 21st century which begins with identifying basic themes and concepts that incorporate multiple subject content on redefining theory of engineering for relevance in VI. EE. Through the integration of science, technology, engineering and technology (STEM), a STEM curriculum exemplifies the cross-curriculum teaching and learning, building a strong intellectual capacity that will match the 21st century curriculum as required in 4IR era (Lloyd et al., 2015). STEM original plans required students to become an active learner who learn important concepts through creative and innovative projects. Thus, engineering students' involvement in problem-solving process build a culture of logical reasoning, in which asking and answering their own questions becomes the centrepiece of the learning process, thereby using high levels of thinking methods as they apply knowledge content in ground-breaking ways (Jiang et al., 2015).

Expanding current engineering practices in Africa will not be enough as highly 21st century engineering educators and professionals do not have the skills development capacity to meet the demands of 4IR era in engineering practices (Hall et al., 2017). Hence, this has some grave consequences for policy relating to the engineering educational workforce. There are a number of better engineering project-based opportunities, involving application of theory of engineering tools in dealing with engineering designs and implementation of new solutions to meet the aforementioned challenges and barriers of changing curriculum, designing a flexible learning environment and expanding students' enrolment and educators training as well as motivation (Reddan, 2017). Engineering curriculum has profound implications to develop capabilities to teach engineering students new skills to maximize their benefit for improved student learning outcomes. Positive changes in desired students' outcomes in taking engineering as a career path also have implications in their capabilities to maximize their benefit for their approved learning outcomes.

In the 21st century, globalization and modernity has fostered technological progress and global growth that involves growing pressure on economic growth of nations with greater inequality in the areas of education in Africa (Pawley et al., 2018). This has fringed on the development of human capacity, with living standards increasingly far below of those in developed nations. Scientific and technological progress undoubtedly improves engineering educational institutions, the intellectual ability and knowledge capacity to deal with social problems and, together with the opening-up of markets and the enhanced competition and efficiency that accompany globalization (Mein et al., 2018). This constitutes a tremendous opportunity to sustainably raise the levels of opulence and well-being of individuals who choose engineering as a career pathway. Higher EE often talks about redefining theory of engineering and its relevance in EE in Africa. Though, few efforts have been made to directly engage engineering educators and students in a dialogue about how to create a friendly curriculum, in accommodating theory and practices in engineering learning (Okay-Somerville and Scholarios, 2017). This will go a long way to merge faculty and institutions as well as professionals to embed in recent technology to help students to learn more effectively with subjects that focused on theory of engineering.

\section{CONCLUSION AND RECOMMENDATIONS}

This paper attempts to show that 21st century has a groundbreaking global perspective on EE and engineering industries, as this is key in redefining theory of engineering for relevance in EE in Africa. Besides, a new paradigm for redefining theory of engineering for its relevance is crucial in achieving the new SDGs targets allied with EE impacts, which will strongly influence development and growth practices in Africa in the 21st century. In addition, the 21st century engineering curriculum needs to be upgraded in order to develop engineering students, especially in an increasingly technological society. Therefore, the curriculum should be research-based, built on collaboration inputs from academic and professional, placing emphasis on the significance of acquiring knowledge and skills needed to tackle engineering problems and proffers solution for engineering impacts on the society.

Subsequently, the focus of the 21st century engineering curriculum should centre on individual students, facilitating full potential intellectual development among undergraduate and graduate engineering students. Engineering bodies and accreditation bodies ae expected to dialogue with various engineering institutions to rebuild engineering higher learning institutions for its significance in EE. This will assist to look at variety of approaches in facilitating the aim of theory of engineering redefine for its relevance in the 21st century Africa.

Published By:
Blue Eyes Intelligence Engineering

and Sciences Publication

(C) Copyright: All rights reserved.

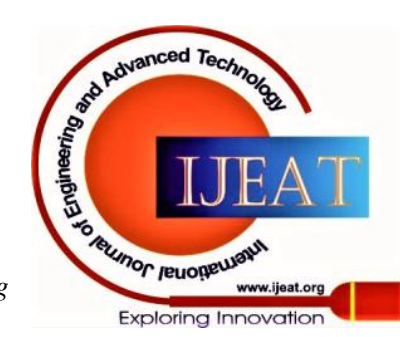


Reshaping EE and EE curriculum in Africa to meet the demands of the 21st century will require input from government, engineering profession, industry and academia. Therefore, major recommended actions are as follows:

1. Government should place engineering teaching quality alongside research excellence in the assessment of funding requirements for engineering higher learning facilities and to increase the institutional funding to cover the true cost of providing world class teaching in engineering.

2. To provide additional funding to engineering accreditation bodies to enable them to expand and support the development of engineering instructive initiatives and dissemination of best practices in EE. The increase in funding in EE initiatives will go a long way to brace up industry links with academia such as professional and academic visiting schemes, which will facilitate introduction of new schemes such as redefining theory of engineering for relevance in the 21st century.

3. Long-term relationships should be actively established with university engineering departments, membership of Engineering Advisory Boards and Industrial Tutors, offering research-based project topics and facilities for students' placements. Industries should also recognize the secondary benefit of engaging in collaboration initiatives, especially in development of younger academia and potential graduates.

4. Accreditation procedures should be ensured in building strategic engineering tools in certifying upgraded relevant courses and curriculum that will encourage course development and innovation, taking into account competent professional that will engage students in redefining engineering theory for its relevance in EE.

\section{REFERENCES}

1. Anderson JR, Reder LM, Simon HA, Ericsson KA, Glaser R (1998). Radical constructivism and cognitive psychology. Brookings Papers on Education Policy; (1): 227-278.

2. Atkinson RK, Derry SJ, Renkl A, Wortham DW (2000). Learning from examples: Instructional principles from the worked examples research. Review of Educational Research; 70 (2): 181-214.

3. Bates L, Hayes H (2017). Using the student lifecycle approach to enhance employability: An example from criminology and criminal Issue); 18 (2): 141-151.

4. Bhattacharya A, Jeong M (2018), Driving the Sustainable Infrastructure Agenda in Emerging Markets, Global Economy and Development at Brookings. Accessed on 19th August, 2020 from https://economic-policyforum.org/wp-content/uploads/2018/11/GIZpaper 20180630 final.pdf . [105]

5. Bhattacharya, A., J. Oppenheim and N. Stern (2015), Driving Sustainable Development Through Better Infrastructure: Key Elements of a Transformation Program, Global Economy and Development at Brookings. Accessed on 29th August, 2020 from https://newclimateeconomy.report/workingpapers/wpcontent/uploads/ sites/5/2016/04/Driving-sustainable-development-throughbetterinfrastructure.pdf.

6. Bilgin AA, Rowe AD, Clark L (2017). Academic workload implications of assessing student learning in work-integrated learning. Asia-Pacific Journal of Cooperative Education (Special Issue); 18 (2): 165-181.

7. Blackmore, P., Bulaitis, Z. H., Jackman, A. H., Tan, E. (2016). Employability in higher education: A review of practice and strategies around the world. Report commissioned by Pearson. Accessed from August 19th, 2020 from https://www.pearson.com/uk /about-us/newsand-policy/reportsandcampaigns/employability-in-highereducation. html

8. Bornasal F., Brown S., Perova-Mello N., Beddoes K. 2018. Conceptual Growth in Engineering Practice. Journal of Engineering Education; 107 (2): 318-348. justice. Asia-Pacific Journal of Cooperative Education (Special

9. Bridgstock R (2017). The university and the knowledge network: A new educational model for Twenty-first Century learning and employability. In M. Tomlinson \& L. Holmes (Eds.), Graduate employability in context. London: Palgrave Macmillan. pp. 339-358

10. Burke C, Scurry T, Blenkinsopp J, Graley K (2016). Critical perspectives on graduate employability. In M. Tomlinson \& L. Holmes (Eds.), Graduate employability in context London: Palgrave Macmillan. pp. 87-107.

11. Chillas S, Marks A, Galloway L (2015). Learning to labor: An evaluation of internships and employability in the ICT sector. New Technology, Work \& Employment; 30 (1): 1-15.

12. Garg A, Shukla B, Gendal G (2015). Barriers to implementation of ICT in educational institutions. The International Journal of Information and Learning Technology; 32: 94-108.

13. Hall M, Pascoe D, Charity M (2017). The impact of work-integrated learning experiences on attaining graduate attributes for exercise and sports science students. Asia-Pacific Journal of Cooperative Education (Special Issue): 18 (2): 101-113.

14. Holmes L (2017). Graduate Employability: Future directions and debate. In M. Tomlinson \& L. Holmes (Eds.), Graduate employability in context (pp. 359-369). London, UK: Palgrave Macmillan. doi:10.1057/978-1-137-57168-7_17

15. Jackson D, Wilton N (2016). Developing career management competencies among undergraduates and the role of work-integrated learning. Teaching in Higher Education; 21 (3): 266-286.

16. Jiang YH, Lee SWY, Golab L (2015). Analyzing student and employer satisfaction with cooperative education through multiple data sources. Asia-Pacific Journal of Cooperative Education; 16 (4) 225-240.

17. Kaider F, Hains-Wesson R, Young K (2017). Practical typology of authentic work integrated learning activities and assessments. AsiaPacific Journal of Cooperative Education (Special Issue); 18 (2): 152164.

18. Kodongo O, Ojah K (2016). Does infrastructure really explain economic growth in Sub- Saharan Africa? Review of Development Finance; 6 (2): 105-125.

19. Leandro Cruz M., Saunders G., Groen P., 2019. Evaluation of competency methods in engineering education: a systematic review. European Journal of Engineering; 1-30.

20. Lloyd K, Clark L, Hammersley L, Baker M, Rawlings-Sanaei F, D'Ath E (2015). Unintended outcomes of university-community partnerships: Building organizational capacity with PACE International partners. Asia-Pacific Journal of Cooperative Education; 16 (3): 163-173.

21. Matthews M (1998). Constructivism in Science Education: A Philosophical Examination. Dordrecht: Springer Science \& Business Media. pp. $\mathrm{x}$.

22. Mein E, Esquinca A, Monarrez A, Saldana C. (2018). Building a pathway to engineering: The influence of family and teachers among Mexican-origin undergraduate engineering students. J. Hispan. High. Educ.; 1: 1-15.

23. Mejia JA, Wilson-Lopez A, Robledo AL, Revelo RA (2017) Nepantleros and nepantleras: How Latinx adolescents participate in social change in engineering. In Proceedings of the ASEE Annua Conference and Exposition, Columbus, OH, USA, 25-28 June.

24. Mejia JA, Revelo RA, Villanueva I, Mejia J (2018). Critical theoretical frameworks in Engineering Education: An anti-deficit and Liberative Approach. Educ. Sci.; 8 (158): 1-13.

25. Morell L (2016). "Disrupting Engineering Education to Better Address Societal Needs," em Proceedings of 2015 International Conference on Interactive Collaborative Learning (ICL), Florence.

26. Nola R, Irzik G (2006). Philosophy, Science, Education and Culture. Springer Science \& Business Media. p. 175.

27. Nowak M, Castellini C, Massironi C (2018). Applying radical constructivism to machine learning: a pilot study in assistive robotics. Constructivist Foundations; 13 (2): 250-262.

28. OECD (2016), A New Rural Development Paradigm for the 21st Century: A Toolkit for Developing Countries, Development Centre Studies, OECD Publishing, Paris. http://dx.doi.org/1 0.1787/9789264252271-en.

29. OECD/ACET (2020), Quality Infrastructure in 21st Century Africa Prioritising, Accelerating and Scaling up in the Context of Pida (2021-30) 
30. Okay-Somerville B, Scholarios D (2017). Position, possession or process? Understanding objective and subjective employability during university-to-work transitions. Studies in Higher Education; 42(7): 1275-1291.

31. Oliver B (2015). Redefining graduate employability and workintegrated learning: Proposals for effective higher education and disrupted economies. Journal of Teaching \& Learning \& Graduate Employability; 6(1): 56-65.

32. Ouhbi S., Idri A., Ferna'ndez-Aleman J.L.,Toval A., 2015. Requirements engineering education: a systematic mapping study. Requirements Eng.; 20:119-138.

33. Oxford Poverty and Human Development Initiative (OPHDI), (2015). Global MPI Data Tables for 2015, database, Oxford Poverty and Human Development Initiative, Oxford, www.ophi.org.uk/multi dimensional-poverty-index/mpi-2015/mpi-data/, accessed 11 August 2015.

34. Pawley A, Mejia JA, Revelo RA, (2018). Translating theory on colorblind racism to an engineering education context: Illustrations from the field of engineering education research with underrepresented populations. In proceedings of the ASEE Annual Conference and Exposition, Salt Lake City, UT, USA, 24-27 June 2018.

35. Piaget J (1971). Psychology and Epistemology: Towards a Theory of Knowledge (New York: Grossman, 1971).

36. Reddan G (2017). Combining quality work-integrated learning and career development learning through the use of the soar model to enhance employability. Asia-Pacific Journal of Cooperative Education (Special Issue); 18(2): 129-139.

37. Sachs J, Rowe A, Wilson M (2017). Good practice report - WIL. Report undertaken for the Office of Learning and Teaching. Accessed on 26th August, 2020 from http://www.olt.gov.au/resource-goodpractice-workintegrated-learning.

38. Sarkar A (2016). Constructivist Design for Interactive Machine Learning. Proceedings of the 2016 CHI Conference Extended Abstracts on Human Factors in Computing Systems. CHI EA `16. New York, NY, USA: ACM. pp. 1467-1475.

39. Seifert K, Sutton R (2009). Educational Psychology: Second Edition. Global Text Project. pp. 33-37.

40. Trede F, McEwen C (2016). Carving out the territory for educating the deliberate professional. In F. Trede \& C. McEwen (Eds.), Educating the deliberate professional. Cham, Switzerland: Springer. pp. 15-28.

41. Trevelyan J. 2019. Transitioning to engineering practice. European Journal of Engineering Education; 44 (6), 821-837.

42. Viegas C, Marques A, Alves G (2016). Engineering and technological learning in educational and professional contexts. em TEEM 2016 Fourth International Conference on Technological Ecosystems for Enhancing Multiculturality, Salamanca, 2016.

43. Viegas C, Marques A, Alves GR (2017). 21st Century Challenges in Engineering and Technological learning. In J. M. Dodero, M. S. Ibarra Sáiz, \& I. Ruiz Rube (Eds.), Fifth International Conference on Technological Ecosystems for Enhancing Multiculturality (TEEM'17) (Cádiz, Spain, October 18-20, 2017) (Article 11). New York, NY, USA: ACM.

44. Wilson-Lopez A., Strong A.R., Hartman C.M., Garlick J., Washburn K.H., Minichiello A., Weingart S., Acosta-Feliz J. 2020. A systematic review of argumentation related to the engineering-designed world. $\mathrm{J}$ Eng. Educ.; 109:281-306.

\section{AUTHOR PROFILE}

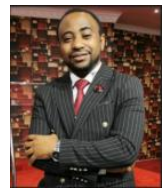

Dr. Kehdinga George Fomunyam, Institute for Systems Science, Durban University of Technology, Durban, South Africa.

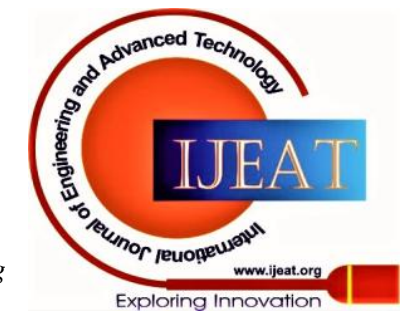

